\title{
Simultaneous tracking of reconnected flux tubes: Cluster and conjugate SuperDARN observations on 1 April 2004
}

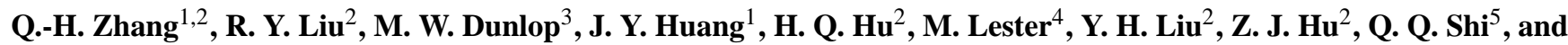 \\ M. G. G. T. Taylor ${ }^{6}$ \\ ${ }^{1}$ School of Science, Xidian University, Xi' an, China \\ ${ }^{2}$ Polar Research Institute of China, Shanghai, China \\ ${ }^{3}$ Rutherford-Appleton Laboratory, Chilton, Didcot, UK \\ ${ }^{4}$ Department of physics and Astronomy, University of Leicester, Leicester, UK \\ ${ }^{5}$ Center for Space Science and Applied Research (CSSAR), Chinese Academy of Sciences, Beijing, China \\ ${ }^{6}$ Research and Scientific Support Department, ESA/ESTEC/SCI-SO Keplerlaan 1,2201AZ Noordwijk ZH, The Netherlands
}

Received: 29 May 2007 - Revised: 6 March 2008 - Accepted: 4 April 2008 - Published: 11 June 2008

\begin{abstract}
While the Cluster spacecraft were located near the high-latitude magnetopause, between 11:30-13:00 UT on 1 April 2004, a series of medium to large scale (40 nT, 0.6$1.2 \mathrm{Re}$ ) FTEs were observed. During this pass, simultaneous and conjugated SuperDARN measurements are available that show a global flow pattern which is consistent with the expected (mapped) north-west motion of (predominantly subsolar) reconnected, magnetic flux at the magnetopause. We focus on analysing the local response of three FTEs, tracking their magnetopause motion via the four-spacecraft measurements together with their corresponding ground mapped motions. For two of these FTEs, where the tracking is strongly coordinated with the ionospheric flow at each footprint of the implied flux tubes in the Northern Hemisphere, conditions corresponded to stable, increasing $\left(>100^{\circ}\right)$ clock angle, while the third event, where the correspondence is less strong, coincided with low $\left(<100^{\circ}\right)$ clock angle. Flux tube motion, both measured and modeled from the inferred Xline, qualitatively matches the clear velocity enhancements in ionospheric convections with northward and westward flow at each location in the Northern Hemisphere, measured simultaneously by SuperDARN, and also roughly matches the observed, south-eastward ionospheric flow in the Southern Hemisphere at the time of these events. The time periods of these velocity enhancements infer that the evolution time of the FTEs is about 4-6 min from its origin on magnetopause to its addition to the polar cap. However, the ionospheric response time in the Southern Hemisphere might be
\end{abstract}

Correspondence to: Q.-H. Zhang

(zhangqinghe@pric.gov.cn)
2 min longer for the 12:31 UT FTE (and 6 min longer for the 12:51 UT FTE) than the response time in the Northern Hemisphere.

Keywords. Magnetospheric physics (Magnetopause, cusp, and boundary layers; Magnetosphere-ionosphere interactions) - Space plasma physics (Magnetic reconnection)

\section{Introduction}

Magnetic reconnection is a commonly accepted process, resulting in energy and momentum transfer from the solar wind to the magnetosphere. The process was first discussed in terms of a steady process by Dungey (1961) and was later discovered to show an independently intermittent and spatially limited nature by Haerendel et al. (1978) and Russell and Elphic (1978) on the dayside magnetopause. The associated magnetic signatures arising from the passage of bundles of reconnected flux nearby a spacecraft were named flux transfer events (FTEs) by Russell and Elphic (1978). This term was originally designed to characterize the signatures according to their bipolar oscillation in the magnetic field component normal to the magnetopause. Subsequent studies detailed the intricate mixing of magnetosheath and magnetospheric plasma populations associated with these signatures (e.g. Daly et al., 1981; Thomsen et al., 1987, Farrugia et al., 1988), the accelerated ion flows (e.g. Paschmann et al., 1982) and their larger occurrence rate during periods of southward interplanetary magnetic field (IMF) (e.g. Berchem and Russell, 1984; Lockwood and Smith, 1992).

Published by Copernicus Publications on behalf of the European Geosciences Union. 
Because of the limitation of single-point spacecraft measurements at the magnetopause, it is difficult to determine the spatial distribution and motion of FTEs. One must compare the in-situ space observations with the response of the ionosphere and the ground geomagnetic field. Part of this response reflects the global flow system and part is directly linked to the bursty and intermittent nature of dayside reconnection. The early work of Elphic et al. (1990) demonstrated that ionospheric flow bursts measured by EISCAT were associated with FTEs observed by ISEE and the first magnetically conjugate measurements of an FTE by Equator-S and of ionospheric flow bursts by SuperDARN were presented by Neudegg et al. (1999). The UV aurora measured by the Polar spacecraft's VIS (Visible Imaging System) Earth camera in the vicinity of the reconnection footprint for this event was later discussed (Neudegg et al., 2001). Recently, Cluster (Escoubet et al., 1997) observations of FTEs (e.g. Owen et al., 2001; Fear et al., 2005; Zheng et al., 2005; Hasegawa et al., 2006) have been combined with a variety of groundbased instruments (e.g. Lockwood et al., 2001; Wild et al., 2001, 2003, 2007; Marchaudon et al., 2004), and with other spacecraft located at the magnetopause (Dunlop et al., 2005). Statistically, the distribution of the repetition rates of pulsed ionospheric flows and poleward moving auroral forms is in agreement with the distribution of FTE occurrence at the magnetopause (McWilliams et al., 2000), although the data sets are typically restricted from the point of view of one-toone measurements. Some questions are still open. For example, the evolution of a flux tube (FTE) from its generation at the magnetopause to its disappearance in the global magnetospheric convection (Amm et al., 2005) is not well tied to the location of reconnection onset or the development of the reconnection rates. The Cluster data set and the subsequent coordination with Double star, has given the opportunity to probe a more direct relationship between measurements at multiple locations on the magnetopause and ground signatures.

In this paper, we present the features of three large, typical FTEs which were simultaneously and conjugately observed by the Cluster array at the high-latitude magnetopause and the SuperDARN radars (Greenwald et al., 1995; Chisham et al., 2007) measuring the global ionospheric convection. Using the Cluster 4-spacecraft observations, we calculated the velocity and the size of the flux tubes. The SuperDARN observations show that the individual flux tube movements, which contain predominantly northward or dawnward components, map to positions in the ionospheric convection cells in the Northern Hemisphere whose flow directions qualitatively correspond to the expected and measured flux tube motion, given a low-latitude reconnection scenario. The presence of (near) subsolar reconnection also results in southeast directed ionospheric flows in the Southern Hemisphere (branch connected to the south cusp). Moreover, we verify that the motion of the reconnected flux tubes are generally consistent with the Cooling model (Cooling et al.,
2001), which predicts the expected motion of reconnected flux tubes, given the prevailing IMF and sheared solar wind flow.

\section{Instrumentation}

The Cluster spacecraft (Escoubet et al., 2001) were launched in pairs in July and August 2000 into elliptical, polar orbits with a perigee of $4 R_{E}$, an apogee of $19.6 R_{E}$ and identical orbital periods of $57 \mathrm{~h}$. Data with $0.2 \mathrm{~s}$ resolution from the fluxgate magnetometer (FGM) (Balogh et al., 1997) on the Cluster spacecraft are used in this study.

The SuperDARN radars (Greenwald et al., 1995; Chisham et al., 2007) measure the line-of-sight (1-o-s) velocity of the ionospheric plasma in 16 adjacent beam directions separated by $3.24^{\circ}$ in azimuth. A full scan, completed in $2 \mathrm{~min}$, thus covers $52^{\circ}$ in azimuth and over $3000 \mathrm{~km}$ in range with a resolution of $45 \mathrm{~km}$. They provide a unique way to directly monitor two-dimensional convection in the high-latitude ionosphere on a global scale. We present the ionospheric convection patterns with the map potential plots, derived by using the technique of Ruohoniemi and Baker (1998), observed by nine of the Northern Hemisphere radars and four of the Southern Hemisphere radars during the interval of interest. The Stokkseyri HF radar is located in western Iceland $\left(63.86^{\circ} \mathrm{N},-22.02^{\circ} \mathrm{E}\right)$ and looks to the west over a section of ionosphere that includes southern Greenland and northeastern Canada.

The solar wind and IMF conditions were measured by the ACE satellite. The ACE spacecraft is located at about (225.1, $38.4,-11.9) \mathrm{R}_{E}$ in Geocentric Solar Magnetic (GSM) coordinates at about 11:20 UT. Using the equation given by Liou et al. (1998):

$t=\left(X_{S C}-X_{B S}-\rho \times B_{X} / B_{\rho}\right) / V_{S W}+5+2$,

we calculated that the transit time of solar wind is about $64 \mathrm{~min}$ from ACE to the Earth's ionosphere. In Eq. (1), $X_{S C}$ and $X_{B S}$ (selected 14.6 $R_{E}$ ) (Fairfield, 1971) are the X-component of the positions of the observing satellite and bow shock in GSM coordinates system, respectively, $\rho=\sqrt{Y^{2}+Z^{2}}$ is the perpendicular distance from the Earth-Sun line to the spacecraft in the $\mathrm{X}-\mathrm{Y}$ plane, $B_{\rho}=\left(B_{Y} \times Y+B_{Z} \times Z\right) / \rho, V_{S W}$ is the speed of solar wind, and 5 and 2 present the transit time of solar wind from bow shock to magnetopause and from magnetopause to ionosphere, respectively. The error of this transit time is about $\pm 5 \mathrm{~min}$. This error did not affect the conclusions very much. The IMF $B_{Z}$ component varied between -3.5 to $2 \mathrm{nT}$, and the $B_{Y}$ were almost always positive, so that the IMF clock angle (if $B_{Z}>0$, Clock angle $=\operatorname{atan}\left(\left|B_{Y}\right| / B_{Z}\right.$ ), and if $B_{Z}<0$, Clock angle $=\mathrm{JI}-\operatorname{atan}\left(\left|B_{Y}\right| / B_{Z}\right)$.) varied from $70^{\circ}$ to $180^{\circ}$ (see Fig. 2). The solar wind density increased from 3 to $4 \mathrm{~cm}^{-3}$ through over the interval of interest, whilst the solar 

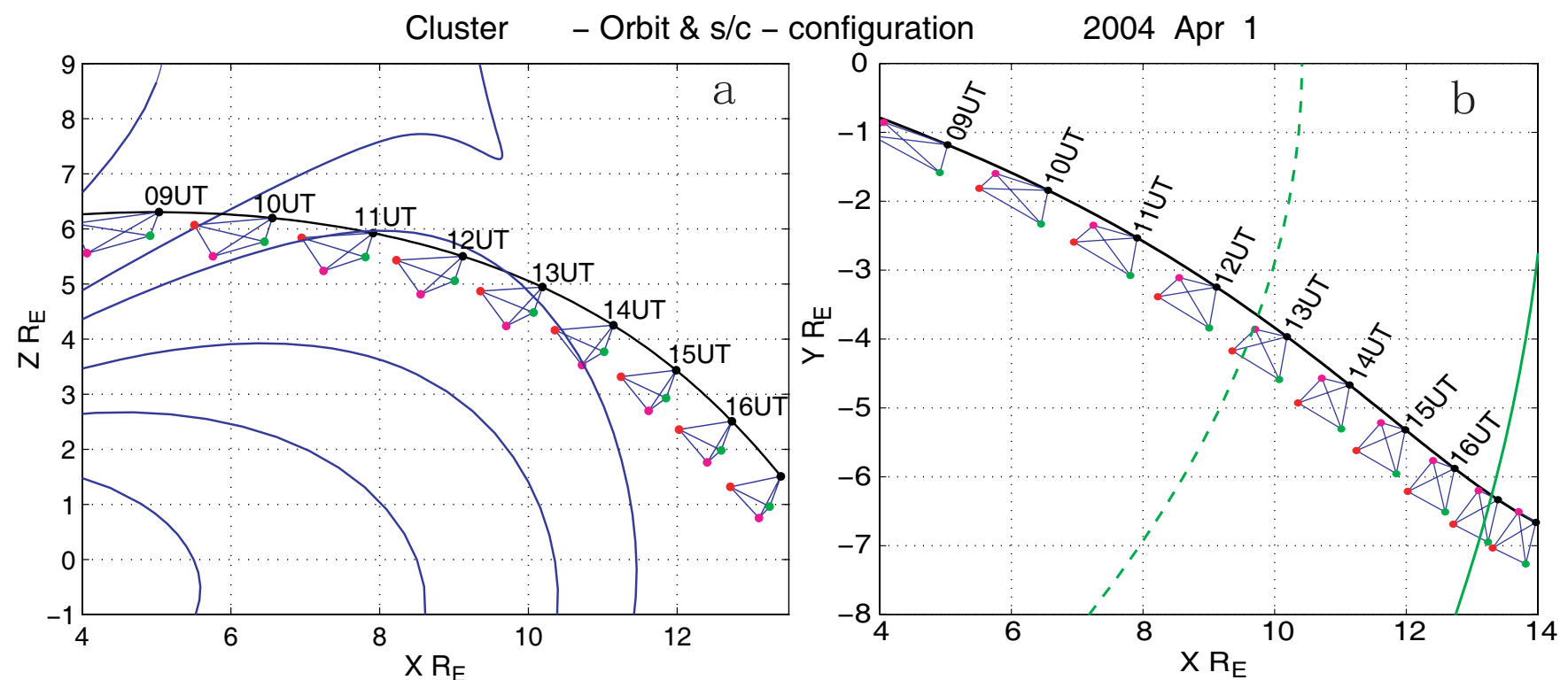

The footprints of Cluster in the Northern and Southern hemispheres
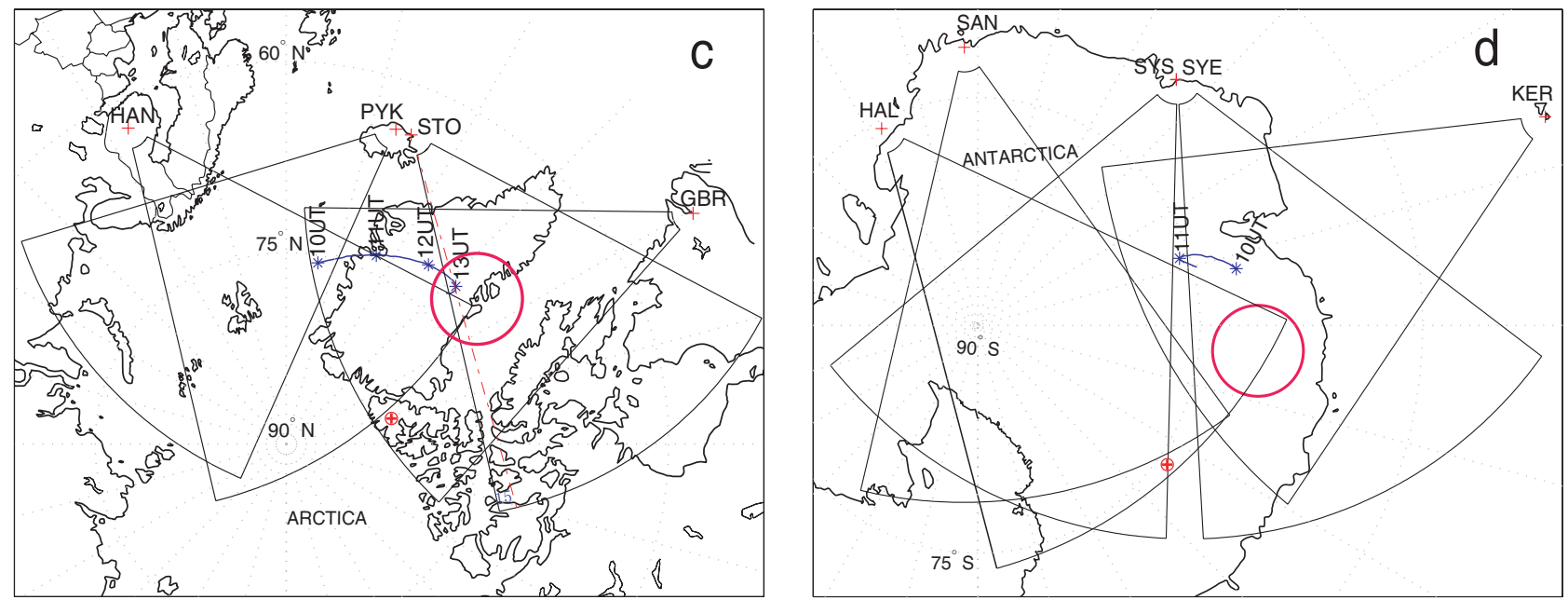

Fig. 1. Cluster spacecraft tracks in the X-Z (a) and X-Y (b) planes in GSM coordinates, together with the ionospheric footprints of Cluster S/C 1 on the maps of Northern (c) and Southern (d) Hemispheres, on 1 April 2004. The orbit also shows the configuration of the Cluster spacecraft array as a tetrahedron (size scaled up by a factor of 20). Model geomagnetic field lines are shown for the projection into the $\mathrm{X}-\mathrm{Z}$ plane and cuts through the bow shock (BS) and magnetopause (MP) are shown for the X-Y plane. The X-Z plane field lines and ionospheric footprints of the spacecraft are drawn from the Tsyganenko ' 96 model with the average inputting parameters: Pdyn=1.35 $\mathrm{nPa}$, IMF $B_{Y}=0.14 \mathrm{nT}$, IMF $B_{Z}=-2.90 \mathrm{nT}$ and $D_{s t}=-10 \mathrm{nT}$. The field-of-view of the CUTLASS radars (HAN and PYK), Stokkseyri radar (STO), and Goose Bay radar (GBR) are presented as a fan in Fig. 1c. The field-of-view of the Halley radar (HAL), Sanae radar (SAN), Syowa South radar (SYS), Syowa East radar (SYE), and Kerguelen radar (KER) are presented as fans in Fig. 1d. The red " $\oplus$ " in Fig. 1c and d represents the geomagnetic north and south pole, respectively. The red circle represents location of the flow region we will examine in Sect. 3 .

wind velocity varied between 418 and $441 \mathrm{~km} / \mathrm{s}$, resulting in a prevailing solar wind dynamic pressure of $\sim 0.9-1.3 \mathrm{nPa}$.

\section{Observations and results}

Figure 1 shows the orbit of the Cluster spacecraft (SC) 1 between 08:00 and 17:00 UT on 1 April 2004, in the X-Z (a) and X-Y (b) planes, in Geocentric Solar Magnetic (GSM) coordinates, and the configuration of the 4-Cluster S/C at intervals along the track (scaled by a factor of 20). Model geomagnetic field lines are shown for the projection into the $\mathrm{X}-\mathrm{Z}$ plane and cuts through the bow shock (BS) and magnetopause (MP) are shown for the X-Y plane. The X-Z plane field lines and $\mathrm{X}-\mathrm{Y}$ plane magnetopause drawn from the Tsyganenko '96 and Shue model, respectively, are also shown, using the parameters: $\mathrm{Pdyn}=1.35 \mathrm{nPa}$ (solar wind 


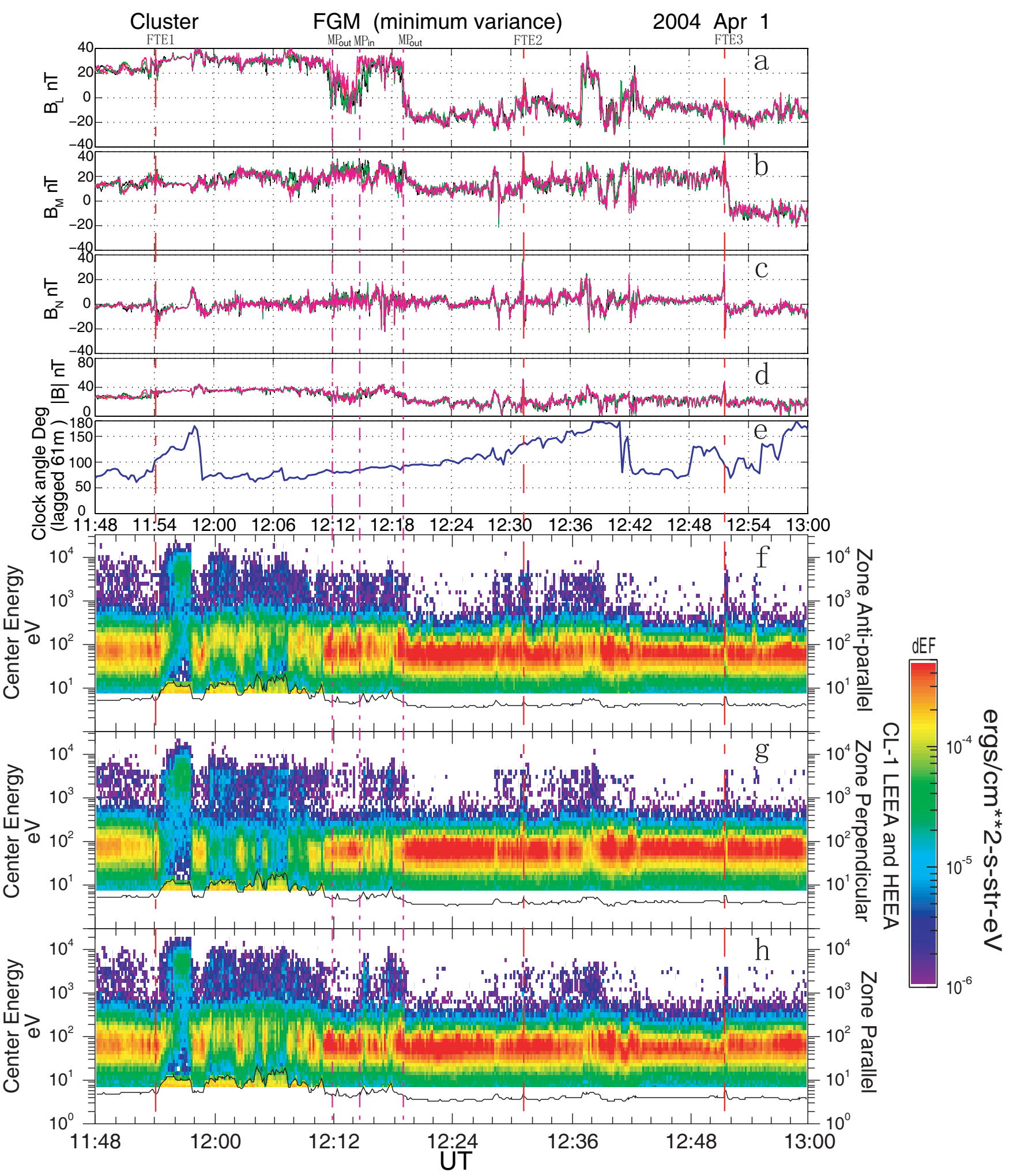

Fig. 2. An overview of the FGM measurements which are projected onto LMN coordinates, and IMF clock angle which are lagged by 61 min, together with the spectrograms of spin-averaged, differential electron energy flux in anti-parallel, perpendicular, and parallel directions from the HEEA and LEEA sensor of PEACE on the Cluster S/C 1, between 11:48 and 13:00 UT on 1 April 2004. The three large, typical FTEs at 11:54:10, 12:31:16 and 12:51:41 UT are highlighted by red dashed vertical lines, and the magnetopause crossings by purple dashed vertical lines. 
dynamic pressure), IMF $B_{Y}=0.14 \mathrm{nT}$, IMF $B_{Z}=-2.90 \mathrm{nT}$ and $D_{s t}=-10 \mathrm{nT}$. These parameters represent the average IMF and solar wind conditions during the interval of interest. The spacecraft cross through the cusp into the high-latitude, dayside plasma sheet, eventually crossing the magnetopause (Fig. 1a and b). The exit into the magnetosheath occurs a little earlier than indicated by the model, just after 12:00 UT. Figure 1c and d show the corresponding ionospheric footprints of Cluster S/C 1 on the Northern and Southern Hemispheres map. The field-of-view of the CUTLASS radars (HAN and PYK), Stokkseyri radar (STO), and Goose Bay radar (GBR) are presented as fans in Fig. 1c with the beam employed in this study indicated by the red dashed line. The field-of-view of the Halley radar (HAL), Sanae radar (SAN), Syowa South radar (SYS), Syowa East radar (SYE), and Kerguelen radar (KER) are presented as fans in Fig. 1d. The red " $\oplus$ " in Fig. 1c and d represents the geomagnetic north and south pole, respectively. The red circle represents location of the flow region we will examine below. In the Northern Hemisphere, the footprints of Cluster are mainly located in the field-of-view of the Goose Bay radar, which has line-ofsight (1-o-s) directions predominantly in the east-west direction over Cluster (see Fig. 1c). Parts of the ground tracks of Cluster are also located in the field-of-view of the CUTLASS radars in the earlier interval when there are few reconnection signatures to be observed. From about 12:30 UT, the footprints of Cluster cross the 1-o-s of the east-most beams of the Stokkseyri radar. The 1-o-s of these beams is mainly in the north-east direction. In the Southern Hemisphere, the footprints of Cluster end after about 11:20 UT and are mainly located in the overlapping region of the field-of-view of the Syowa East and Kerguelen radars.

Figure 2 plots the interval of interest for the magnetic field data from all 4 Cluster S/C, together with the IMF clock angle, lagged by $61 \mathrm{~min}$, i.e. the convection time from ACE to Cluster. The lower panels show the spectrograms of spinintegrated, electron differential energy flux in anti-parallel, perpendicular, and parallel directions from the HEEA and LEEA sensors of PEACE instrument on the Cluster S/C 1. The magnetic field data are expressed in local boundary normal coordinates (LMN), which are found by performing the minimum variance analysis (MVA) on the local magnetopause crossing (marked by purple dashed vertical lines Fig. 2) of Cluster S/C 1 between about 12:10 and 12:24 UT to obtain the mean boundary normal $\mathbf{n}$, where $\mathbf{l}=(-0.52,0.22$, $0.83), \mathbf{m}=(0.04,0.97,-0.23)$ and $\mathbf{n}=(0.85,0.09,0.51)$ in GSM coordinates. This normal is typical for the location of Cluster on the magnetopause. The clock angle shows a sequence of slow changes, but monitors a predominantly eastward, and southward IMF direction and the interval contains a number of clear reconnection signatures of varying size. The PEACE data shows that the Cluster S/C 1 was in the magnetosheath, went into the dayside plasma sheet for a short time around about 11:53 UT, and later sampled a boundary layer with lower than normal magnetosheath fluxes during about 11:58 to 12:10 UT. After about 12:14 UT, S/C 1 re-enters the magnetosheath. During the interval of interest, four magnetospheric and eight magnetosheath standard bipolar signatures in the $B_{N}$ component (see Fig. 2c) are observed by Cluster with an increasing total $|B|$ (see Fig. 2d) and a clear mixing of magnetosheath and magnetospheric plasma populations (see Fig. $2 \mathrm{f}-\mathrm{h}$ ). The timing difference of these signatures is very small and the perturbations in the $B_{N}$ component and magnitude of the magnetic field are much greater than the background magnetosheath fluctuations, which indicated that the signatures are FTEs and not surface waves (Song et al., 1994). The variations of magnitude between the positive and negative peaks in the $B_{N}$ signature of the magnetosheath FTEs are much larger than the corresponding ones in the magnetospheric FTEs.

Based on the peak-to-peak magnitude of the FTEs, we select, for illustration and detailed analysis, one of the largest magnetospheric FTE at 11:54:10 UT and two of the largest magnetosheath FTEs at 12:31:16 UT and 12:51:41 UT, respectively, which are highlighted by the red dashed vertical lines in Fig. 2. In fact, all FTEs in the interval show standard polarity (Russell and Elphic, 1978), bipolar signatures in the $B_{N}$ component in all spacecraft and the remaining signatures not highlighted here show broadly similar properties. This suggests that northward moving flux tubes are sampled by Cluster (consistent with its high latitude location), connected to the northern cusp and arising from a low-latitude reconnection site. Inspection of the solar wind conditions shows that the IMF clock angle (fourth panel from top of Fig. 2) exhibited repeated periods of an increasing southward IMF component $\left(85^{\circ}\right.$ to $\left.170^{\circ}\right)$, favouring a high reconnection rate, although the 12:51 UT FTE occurred during more variable conditions.

Since all 4 spacecraft sample these FTEs, we may apply a number of four-spacecraft techniques (timing analysis (Russell et al., 1983; Harvey, 1998; Dunlop et al., 2001) and Spatio-temporal Difference (Shi et al., 2006)) to calculate the motion and scale of the FTEs observed by Cluster in each case using the tetrahedral spacecraft configuration. The results are almost the same. For the 11:54 UT event, the speed and the direction of the motion is: $U n=102 \mathrm{~km} / \mathrm{s}, \boldsymbol{n}=(-0.64,-0.63,0.43)$, confirming the northward motion, but having a strong dawnward (westward) component. Assuming the flux tube as a cylinder, the velocity and the duration of the whole bipolar signature $(38 \mathrm{~s})$, give an estimated (minimum) flux tube size of $0.61 R_{E}$. For the $12: 31 \mathrm{UT}$ event, $U n=179 \mathrm{~km} / \mathrm{s}, \boldsymbol{n}=(-0.50$, $-0.21,0.83)$, giving a stronger northward component, but still westward, and the corresponding flux tube size was estimated as $0.92 R_{E}$. For the $12: 51 \mathrm{UT}$ event, $U n=218 \mathrm{~km} / \mathrm{s}$, $\boldsymbol{n}=(-0.20,-0.05,0.98)$, giving a strong northward component and no clear dawn/dusk motion. The corresponding flux tube size was $0.88 R_{E}$. These individual motions were checked using the deHoffmann-Teller (deHT) analysis by inputting the Cluster FGM and CIS plasma data. The results 


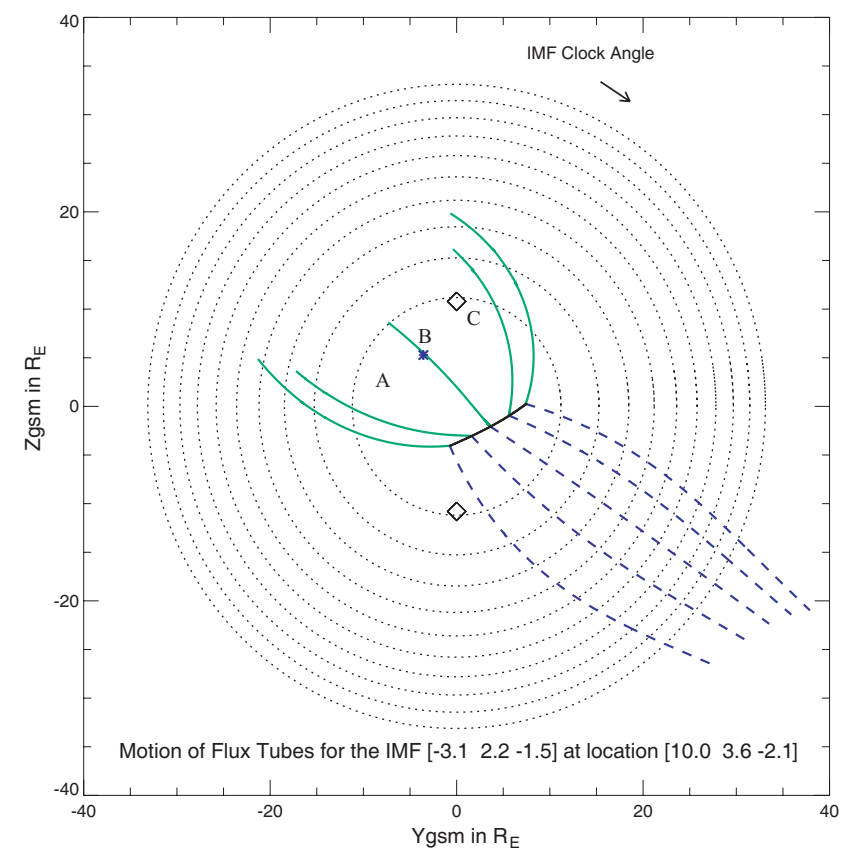

Fig. 3. Motion of reconnected flux tubes for low-latitude reconnection under mean IMF conditions, which is obtained by running the Cooling model. The reconnection conditions are satisfied along a merging line, the projection of which is indicated by the black diagonal line in the middle of the figure. The solid lines indicate the trajectories of tubes which connect to the northern cusp, and the dashed lines indicate those which connect to the southern cusp. The position of Cluster is represented by the blue star dot.

are as follows. For the 11:54 UT event, the running time period is about 11:53:58-11:54:36 UT, $\left|V_{h t}\right|=279.65 \mathrm{~km} / \mathrm{s}$, $V_{h t} /\left|V_{h t}\right|=(-0.57,0.45,0.69)$; for the 12:31 UT event, the running time period is about 12:31:01-12:31:33 UT, $\left|V_{h t}\right|=237.75 \mathrm{~km} / \mathrm{s}, V_{h t} /\left|V_{h t}\right|=(-0.51,0.06,0.86)$; for the 12:51 UT event, the running time period is about 12:51:1712:51:45 UT, $\left|V_{h t}\right|=288.24 \mathrm{~km} / \mathrm{s}, V_{h t} /\left|V_{h t}\right|=(-0.61,-0.19$, 0.77). The results of the last two events, give broadly similar directions and magnitudes as for the 4 S/C results, but FTE1 shows a duskward motion. In fact the Walèn test is approximately satisfied only for the central regions of FTE1 (with a linear correlation coefficient of about 0.98 and a slope of about 0.61 ) and may be in error. We feel that deHT analysis in the region surrounding the flux tube may not give accurate results. They do however serve to broadly confirm the $4 \mathrm{~S} / \mathrm{C}$ results, at least for the last two FTEs. We note that the earlier two FTEs occurred under increasingly southward IMF, but that the last occurred under variable IMF and low clock angle. These motions confirm the evolution of the northward flux tube branch as it is dragged across the magnetopause, as sampled momentarily by Cluster at its particular location. We also checked the plasma data from CIS instrument onboard Cluster S/C 1 and found that the ion velocity is also distinctly increased and deflected within the FTEs, as well as in the magnetopause boundary layer. The direction (predominantly northward and westward) is consistent with the stress balance expected for pulsed reconnection.

In order to place the motion of the FTEs in context, the Cooling model (Cooling et al., 2001) is applied, which examines the predicted motion of reconnected magnetic flux tubes over the surface of the magnetopause, and the results are shown in Fig. 3. The view shows the YZ plane, looking Earthward from the Sun. The dotted circles indicate the radius of the magnetopause at $\mathrm{X}$-coordinate intervals of $5 R_{E}$. The innermost circle represents $X=\frac{1}{2} R_{M P}$ and contains the estimated position of the cusps (diamonds). For the figure, we used the average input parameters for the three FTEs with $n_{p}=3.5 / \mathrm{cm}^{3}$ (solar wind proton number density), $V_{S W}=425 \mathrm{~km} / \mathrm{s}$ (solar wind speed), IMF $B(x, y, z)=(-3.1$, $2.2,-1.5) \mathrm{nT}, R_{b}=13.5 R_{E}$ (the stand-off distance of the bow shock), $R_{M P}=11.5 R_{E}$ (the stand-off distance of the magnetopause) and (Ygsm, Zgsm) $=(-3.5,5.3) R_{E}$ (the average Cluster position in GSM YZ plane). The expected orientation of the merging line in the component merging model is indicated by the black diagonal line in the middle of the figure, where its length has been limited to an arbitrary maximum of $10 R_{E}$ and the model allows the position relative to the subsolar point to be chosen, which can be slightly moved in a limited region. The results led by this slight motion could not affect this study so much. Pairs of open reconnected flux tubes are assumed to be initiated at positions along the merging line and their motion is calculated in the model over a period of $800 \mathrm{~s}$, resulting in the fan of motion tracks displayed (see Cooling et al., 2001, for details). The expected trajectories of tubes which connect to the northern cusp are indicated by the solid lines, the dashed lines indicating those which connect to the southern cusp. The average position of Cluster is represented by the blue star dot and it is clear that the spacecraft may observe a variety of motions depending on precise conditions which will control the relative location of the Cluster array with respect to the fan. This location will change in particular for the changing IMF orientation (the relevant effect for this event) and different choices of the X-line position will effectively move the Cluster array to one side or another of the fan of tracks. Although the parameters used are approximately valid for all three FTEs, the spread in the fan of northern tracks is somewhat sensitive to the IMF clock angle (widening for lower values). The range of positions covering the observed flux tube motions for the northern branch is indicated as A, B, and C: those flux tubes passing through the A region are mainly moving dawnward; at $\mathrm{B}$ they move north-westward, and at $\mathrm{C}$, they mainly move northward. The expected motion at the locations $\mathrm{A}, \mathrm{B}$, or $\mathrm{C}$ are consistent with the flux tubes observed at 11:54, 12:31, and 12:51 UT, respectively. In particular, the strong northward component of the last FTE can be consistent with the lower clock angle observed at that time (wider fan). At lower clock angles the expectation is that the dawn-dusk component of the motion will be unstable and this is born out by 

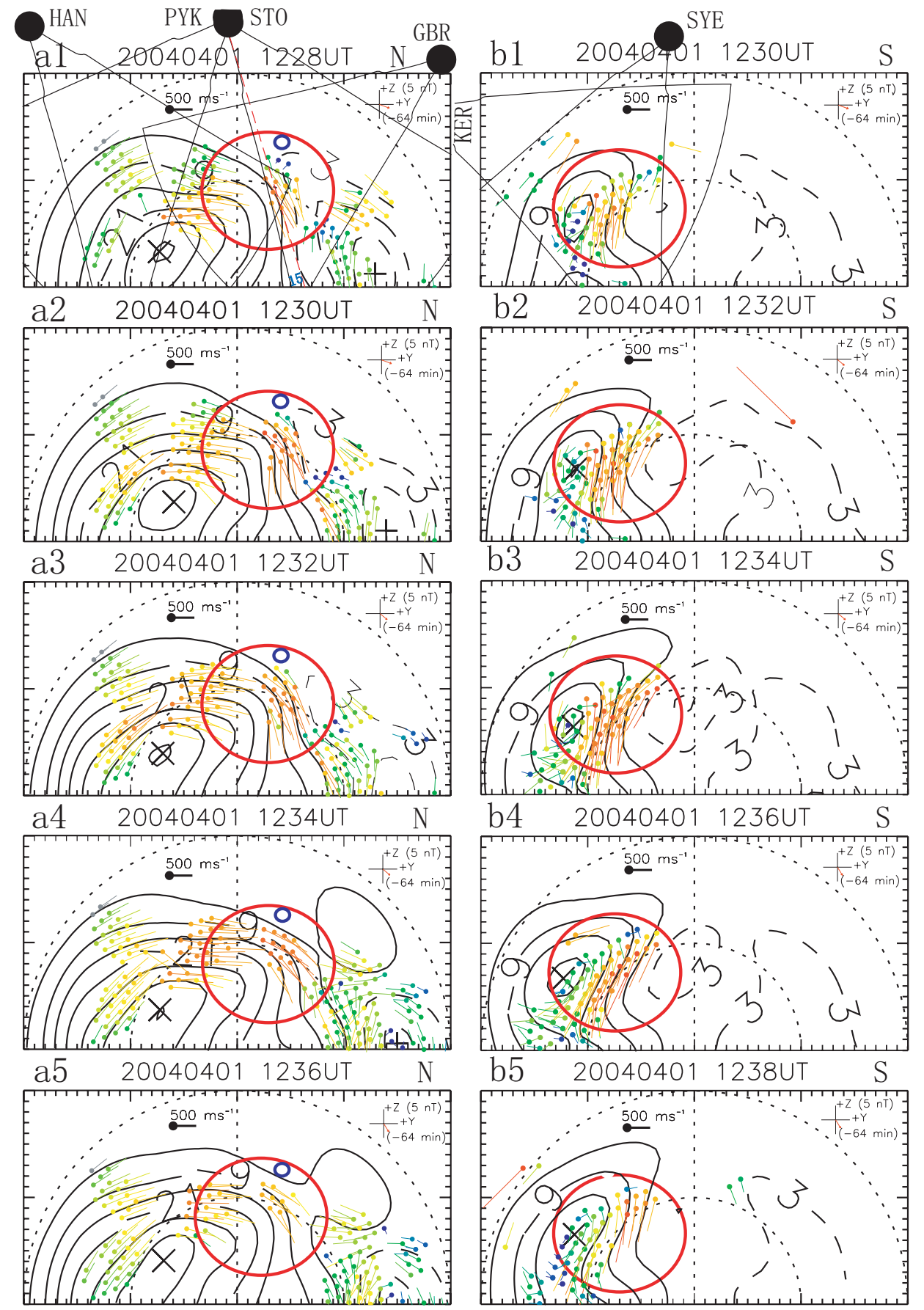

Fig. 4. Streamlines and vectors of the ionospheric flows derived from the northern (a1-5, c1-6) and southern (b1-5, d1-6) hemispheric SuperDARN velocity measurements shown on geomagnetic grids, obtained from the "map potential" algorithm. Maps are shown from 12:28 to 12:36 UT and 12:46 to 12:56 UT for the Northern Hemisphere and from 12:30 to 12:38 UT and 12:52 to 13:02 UT for the Southern Hemisphere. The field-of-view of the CUTLASS radars (HAN and PYK), Stokkseyri radar (STO), Goose Bay radar (GBR) and the Syowa East radar (SYE), Kerguelen radar (KER) are presented as fans in Fig. 4a1 and b1, respectively. The direction and magnitude of the lagged IMF are indicated at the right-hand upper corner of each map. The small blue circle is the footprint of the Cluster spacecraft. 

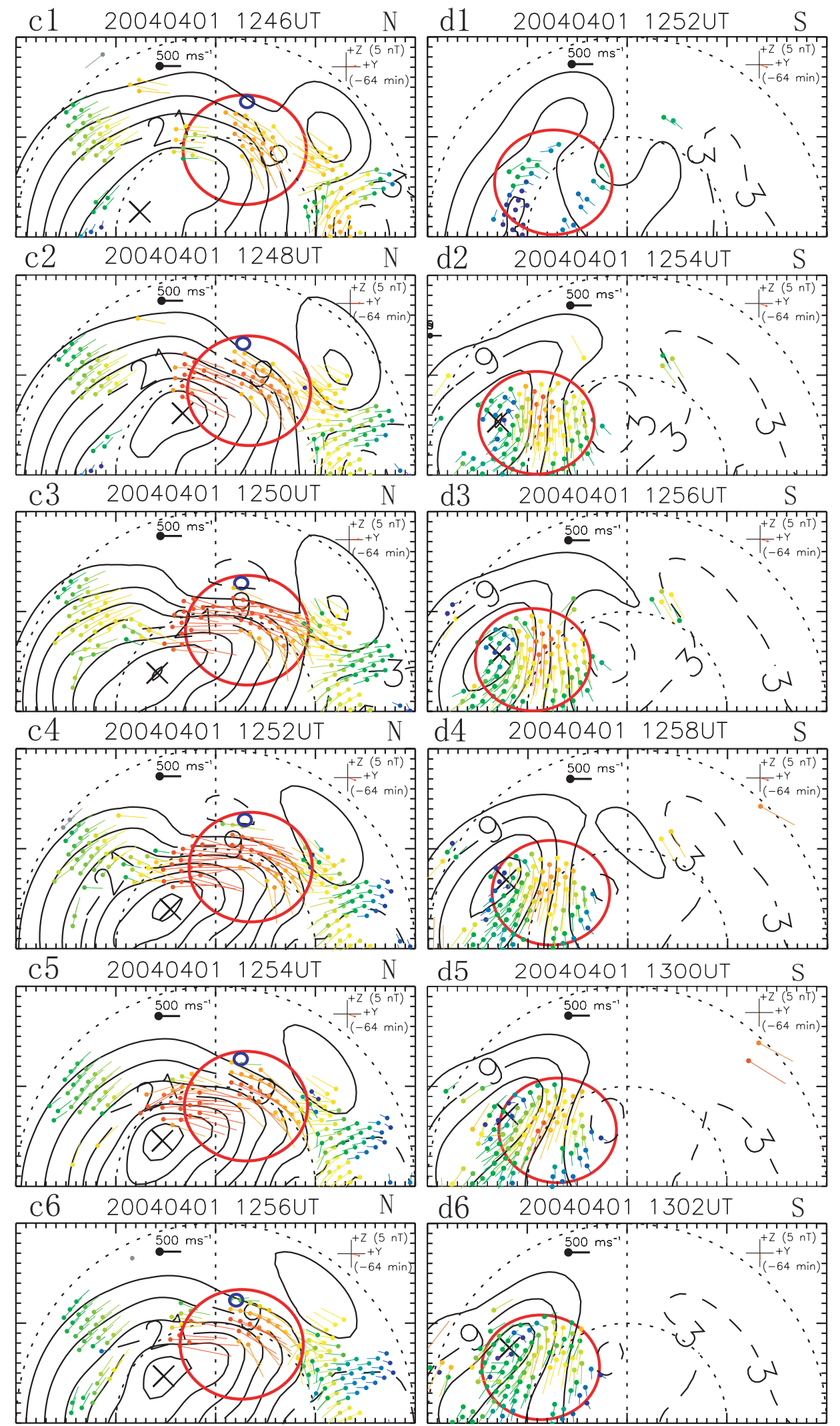

Fig. 4. Continued. 
most of the FTEs analysed. By contrast, the expected motions of the southern branches are all south-eastward in the model. We therefore have a clear prediction for the evolution of reconnected flux tubes, which identifies the origin of each of the highlighted FTEs.

To pursue these predictions further we investigate the corresponding ionospheric conditions with the intention to compare inferred motion of the FTEs footprints to the local flow directions in the convection maps. Figure 4 presents two minute averaged ionospheric convection patterns observed by the SuperDARN radar in both hemispheres. The region containing, and north of, the Cluster track, in particular, is covered by the Stokkseyri, Goose Bay and CUTLASS radar field-of-view (see Fig. 1c). The predominantly eastward IMF will result in a dominant dusk-side convection cell and an increasing clock angle should result in an ionospheric convection flow enhancement (Lockwood et al., 2003). The mapped motion of individual flux tubes, although not precise, may be expected to correspond to the local flow observed at their footprints and the changing, but predominantly eastward IMF allows us to test this to some degree. Figure 4 shows successive flow maps for the Northern Hemisphere from 12:28 to 12:36 UT (a1-5) and 12:46 to 12:56 UT ((c16) and for Southern Hemisphere from 12:30 to 12:38 UT (b1-5) and 12:52 to 13:02 UT (d1-6). Unfortunately, there is only sparse data for the ionospheric convection corresponding to the 11:54 UT event, although the conditions are very similar to the 12:31 UT event. Grayed concentric circles indicate lines of constant magnetic latitude in $10^{\circ}$ increments. Noon is located at the top of each pattern. The IMF $B_{Y}$ and $B_{Z}$ is shown as a vector in the $\mathrm{YZ}$ plane and the time delay from ACE to the ionosphere is presented at the top right of each pattern (64 min, i.e. $61 \mathrm{~min}$ from ACE to Cluster, mainly in the magnetosheath, plus $3 \mathrm{~min}$ to account for the travel time to the ionosphere). The field-of-view of the CUTLASS radars (HAN and PYK), Stokkseyri radar (STO), and Goose Bay radar (GBR) are presented as fans in Fig. 4a1 with the beam employed in this study indicated by the red dashed line. The field-of-view of the Syowa East radar (SYE) and Kerguelen radar (KER) are also presented as fans in Fig. $4 \mathrm{~b} 1$. The red circle highlights the region of velocity enhancement, as indicated by increased numbers of red drift vectors. In the Northern Hemisphere, the red circle mainly located in the field-of-view of the Goose Bay radar and partly dropped into the 1-o-s of the east-part beams of the Stokkseyri radar. Unfortunately, the data from Goose Bay radar are rather sparse throughout the period under study, so the statistical convection model (Ruohoniemi and Greenwald, 1996), which in the absence of data is used by the map potential algorithm to close the spherical harmonics expansion of the potential (Ruohoniemi and Baker, 1998), played an important role in determining the convection maps. The real ionospheric flows near MLT noon could be closer to line-of-sight of Beam 15 of the Stokkseyri radar than to the reconstructed vectors. In the Southern Hemisphere, the red circle located in the over- lapping region between the field-of-view of the Syowa East radar and Kerguelen radar. However, the highlighted convections mainly rely on the Syowa East radar data measured at the beams which are directed roughly anti-sunward. The 1-o$s$ velocities of the Kerguelen radar are partly bent by the map potential software towards a more tailward flow and adjusted to the prevailing Syowa East radar data.

The propagation delay to the ionosphere from the magnetopause of reconnection signatures is about $2 \mathrm{~min}$, so the maps at 12:34 and 12:54 UT correspond temporally to 12:31 UT and 12:51 UT events, respectively. In each panel of Fig. 4, there are clear velocity enhancements at the nearnoon, high-latitude section on the afternoon cell from 12:30 to $12: 34 \mathrm{UT}(\mathrm{a} 2-\mathrm{a} 4)$ and $12: 48$ to $12: 54 \mathrm{UT}(\mathrm{c} 2-\mathrm{c} 5)$ in the Northern Hemisphere and from 12:32 to 12:36 UT (b2-b4) and 12:54 to 13:00 UT (d2-d5) in the Southern Hemisphere, which correspond to the response of the 12:31 and 12:51 UT events, respectively. The small blue circle is the footprint of the Cluster S/C 1 at 12:31 UT (in Fig. 4a1-5) and 12:51 UT (in Fig. 4c1-6). Near these positions, the drift vectors in the flow cell turn from strongly dawn-ward to strongly northward. Depending on the precise location of the footprint of each FTE (which will be adjacent to, but not at, the Cluster footprint), and allowing for the variable IMF orientation, this is in good agreement with the expectations from both the Cooling analysis and the Cluster observations. We expect the convection situation at the 11:54 UT event to be similar to the 12:31 UT FTE, although the precise mapping around the edge of the flow cell will differ slightly. The Cluster location is therefore poised above the turning in the flow around the convection cell, from predominantly westward to northward. We note that the mapped positions referring to $\mathrm{A}$ and $\mathrm{C}$ in Fig. 3 are Eastward and Westward of the blue circle, representing the Cluster footprint, respectively, and therefore fall near westward, then northward, flows, respectively. We also note that the Cluster position lies on magnetospheric field lines computed from the Tsyganenko ' 96 model, rather than at the boundary, and therefore that the computed footprints lie slightly equatorward of the likely true locations. These points suggest that at least the two later FTEs have motions which reflect the likely flow directions at the respective positions of their footprints. The convection cell pattern infers a relatively direct global context for the evolution of the sampled FTEs.

The drift vectors in the afternoon normal cell in the Southern Hemisphere are consistently south-eastward (panels in Fig. $4 \mathrm{~b}$ and d), roughly in agreement with the predicted direction from the Cooling analysis. The flows for the 12:51 UT event show a less stable flow pattern, just west of the Cluster location, which is consistent with the unstable clock angle at that time. These comparisons further suggest the formation of an extensive, low latitude merging line, with a reconnection geometry reflected in the observed FTE motions. Comparing the ionospheric convections in both hemispheres, we find the velocity enhancements lasted about 4 min for 
the 12:31 UT event and $6 \mathrm{~min}$ for the 12:51 UT event, which inferred that the evolution time of FTEs is about 4-6 min from its origin on magnetopause to its addition to the polar cap. However, the ionospheric response time in the Southern Hemisphere might be 2 min longer for the 12:31 UT FTE and $6 \mathrm{~min}$ longer for the 12:51 UT FTE than in the Northern Hemisphere. Does this suggest the reconnection site is located northward of the subsolar region? This might need better data coverage in the Southern Hemisphere to show the further evidence or be because of a different conductivity in the northern and southern high-latitude ionosphere. Whilst the intensities of the velocity enhancements are almost the same in both hemispheres for the 12:31 UT event, they are much stronger in the Northern Hemisphere than in the Southern Hemisphere for the 12:51 UT event. The convection signatures therefore show that there is a good response to the IMF conditions resulting in clear antisunward ionospheric convections at the cusp regions of both hemispheres, consistent with the onset of low-latitude reconnection and consistent with a predominantly eastward IMF.

Finally, we compare the behaviour of possible signatures of "poleward moving radar auroral forms" (PMARFs), which have previously been identified as the radar backscatter equivalent of the auroral signature of FTEs (Wild et al., 2001, 2003) and "pulsed ionospheric flows" (PIFs), which are thought to be the radar flow signatures of FTEs (Pinnock et al., 1995; Provan et al., 1998). These signatures are not found in the ionospheric scatter or line of sight velocity data from the Goose Bay radar, which has rather sparse data throughout the period under this study. This might be due to this radar not having an optimum look direction for such events, the 1-o-s being in the east-west direction over Cluster; the majority of our FTE's have significant northward components. Signatures of PIFs are not found in the 1-o-s velocity of the CUTLASS radars either. These have field-of-view which overlap with the Cluster 1 orbit track only during the early interval (10:00-11:00 UT), which contains no FTE signatures at Cluster. For the later interval Cluster has moved away from the CUTLASS radar field-of-view and so the radars are less relevant to investigate correspondence with the FTE occurrence. The observations of the east-most beams of the Stokkseyri radar, however, which are directed predominantly northward, do overlap with the later interval containing FTEs at Cluster (12:30-13:00 UT), and so can be used to examine the ionospheric response to at least the later FTEs measured by Cluster. As discussed the last FTE at 12:52 UT, in particular, has a strong northward motion and should be well resolved in the 1-o-s.

Figure 5 shows the backscatter power in (a), 1-o-s Doppler velocity in (b) and Doppler spectral width in (c) measured by the Stokkseyri SuperDARN radar during the period 11:4813:00 UT on 1 April 2004. In Fig. 5a, the backscatter power shows that the FTEs result in clear PMRAFs, marked by the black dashed bias lines. The 1-o-s velocity shows that the ionospheric convections are all anti-sunward flows (see
Fig. 5b) with clearly "pulsed ionospheric flows" (PIFs). During the period before $12: 30 \mathrm{UT}$, it is difficult to clearly distinguish the response to the FTEs observed by Cluster oneto-one with the PIFs. We suppose this is because Cluster is seeing FTEs which occur at locations eastward of the beam. The wide values of the spectral width show a few clear cusp features between 76 and $82^{\circ}$ (see Fig. 5c), which can be taken as the further evidence of the FTEs resulting in strong ionospheric response in the cusp region. The FTEs seen between 12:30 and 13:00 UT, however, do occur during corresponding PIFs and we have indicated the times on Fig. 5. It should be noted that the transit time across the magnetopause $(6-10 \mathrm{~min})$ is of the order of the duration of the PIF signatures along the beam direction and for both selected FTEs at 12:31 and 12:51 UT, the occurrence at Cluster lies at similar latitudes along the 1-o-s. This strongly suggests that the PIF signatures directly correspond to these FTEs (the FTE at 12:40 UT, not analyzed explicitly also corresponds to a PIF signature at 12:42 UT). Thus both the presence of the PIF signatures in Stokkseyri radar and lack of them in CUTLASS Radars, give an additional confirmation of the motion of the reconnection signatures.

\section{Summary}

In summary, we have presented features of three large, typical FTEs which are confirmed by simultaneous and conjugate observations by the Cluster array at the high-latitude magnetopause and the SuperDARN radars measuring the global ionospheric convection. Using the Cluster 4-spacecraft observations, we calculated the velocity and the size of the inferred, reconnected flux tubes as they pass by the Cluster array. These are shown to move tailward, together with both dawnward and northward velocity components under the stable interplanetary magnetic field (IMF) and high clock angle conditions. Under the unstable IMF and low clock angle conditions, for example, the motion is more northward, and for stable, eastward IMF the motion has a stronger westward motion.

The FTE motions are therefore consistent with the expected motion of reconnected magnetic flux tubes over the surface of the magnetopause, arising from a predominantly low-latitude reconnection site during the prevailing IMF and solar wind conditions. The simultaneous measurements show that flux tube motion is also consistent with the observed velocity enhancements and flow directions in the ionospheric convections in the Northern Hemisphere. The flux tube footprints map to clear positions in a predominantly two-cell convection pattern, which are temporally correlated with the ionospheric footprints of the FTEs. The presence of a sub-solar reconnection line at the time of these events also results in the observed, roughly south-east directed ionospheric flows in the Southern Hemisphere. The time durations of the velocity enhancements in the Northern 


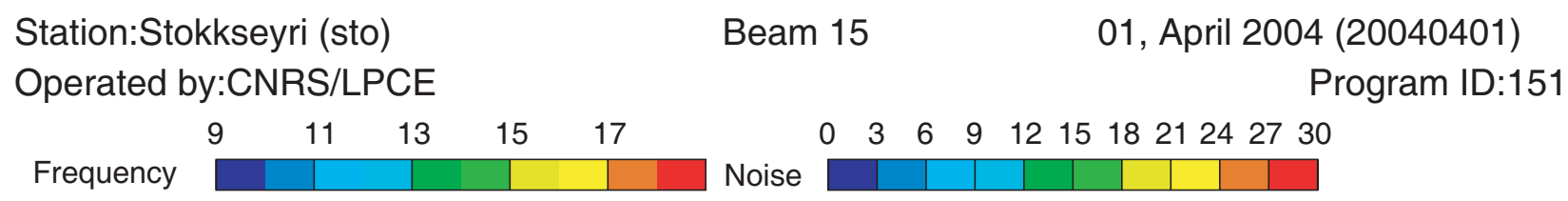

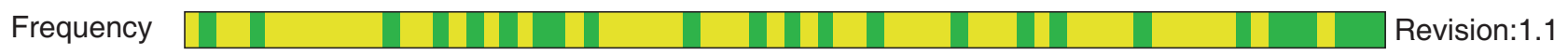
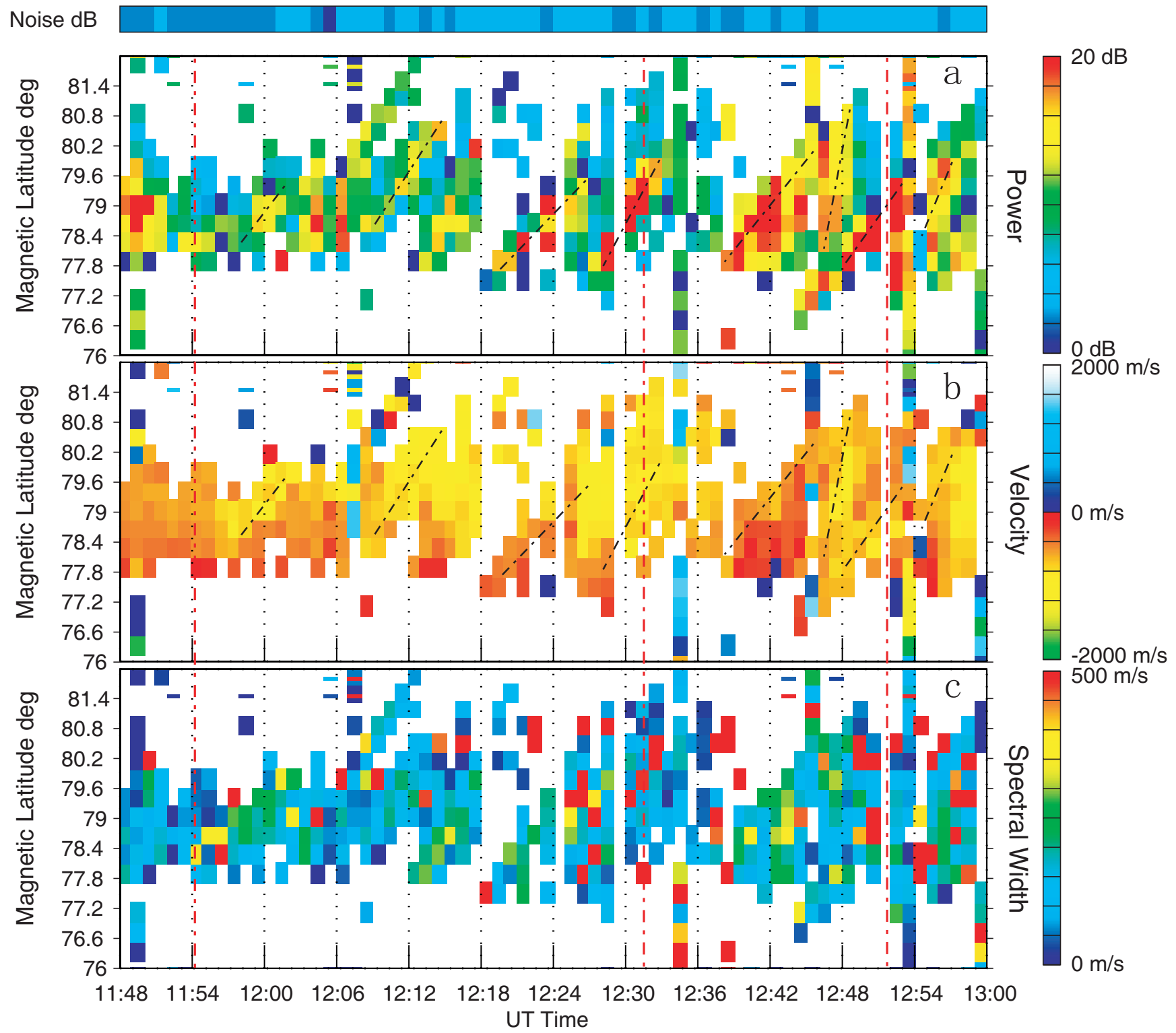

Fig. 5. Backscatter power (a), 1-o-s Doppler velocity (b) and Doppler spectral width (c) measured by the Stokkseyri SuperDARN radar during the period 11:48-13:00 UT on 1 April 2004.

Hemisphere infer that the evolution time of FTEs is about 4-6 min from its origin on magnetopause to its addition to the polar cap. However, the ionospheric response time in the Southern Hemisphere might be 2 min longer than the response time in the Northern Hemisphere, for the 12:31 UT FTE, and 6 min longer, for the 12:51 UT FTE.
Finally, in support of this interpretation via the convection maps, we have been able to identify PIF signatures in the 1-o-s data for at least one, northwardly directed, radar beam which overlaps with the ionospheric Cluster positions for the later FTE observations. Whereas in general there is no one-to-one correspondence between PIF and FTE signatures, 
because of the effects of local sampling at Cluster and projection along the beam direction, the last few FTEs are observed during each of the corresponding PIFs. The last FTE at 12:52 UT, having the strongest northward motion, shows the most significant enhancement in the ionospheric data, as expected.

Acknowledgements. This work is supported by the National Natural Science Foundation of China (grant 40390154, 40236058, 40574075). M. W. Dunlop is supported in the UK by the Science and Technology Facilities Council Rolling Grants. M. Lester is supported by STFC grant PP/E000983. We acknowledge the NASA CDAWeb site to supply us the solar wind and IMF data from the ACE spacecraft, and the SuperDARN portal web site to provide us the Stokkseyri radar observation data. We also thank the Cluster FGM Operations Team and FGM PI, E. A. Lucek, for the magnetic field data, and the Cluster PEACE Operations Team and PEACE PI, A. N. Fazakerley, for the electron spectrometer data.

Topical Editor I. A. Daglis thanks J. De Keyser and another anonymous referee for their help in evaluating this paper.

\section{References}

Amm, O., Donovan, E. F., Frey, H., Lester, M., Nakamura, R., Wild, J. A., Aikio, A., Dunlop, M., Kauristie, K., Marchaudon, A., McCrea, I. W., Opgenoorth, H. J., and Strømme, A.: Coordinated studies of the geospace environment using Cluster, satellite and ground-based data: an interim review, Ann. Geophys., 23, 21292170, 2005, http://www.ann-geophys.net/23/2129/2005/.

Balogh, A., Dunlop, M. W., Cowley, S. W. H., Southwood, D. J., Thomlinson, J. G., et al.: The Cluster magnetic field investigation, Space Sci. Rev., 79, 65-91, 1997.

Berchem, J. and Russell, C. T.: Flux transfer events on the magnetopause: Spatial distribution and controlling factors, J. Geophys. Res., 89, 6689-6703, 1984.

Chisham, G., Lester, M., Milan, S. E., Freeman, M. P., Bristow, W. A., Grocott, A., MacWilliams, K. A., Ruohoniemi, J. M., Yeoman, T. K., Dyson, P., Greenwald, R. A., Kikuchi, T., Pinnock, M., Rash, J., Sato, N., Sofko, G., Villain, J.-P., and Walker, A. D. M.: A decade of the Super Dual Auroral Radar Network (SuperDARN): Scientific achievements, new techniques and future directions, Surv. Geophys., 28, 33-109, 2007.

Cooling, B. M. A., Owen, C. J., and Schwartz, S. J.: Role of the magnetosheath flow in determining the motion of the open flux tubes, J. Geophys. Res., 106, 18 763-18 775, 2001.

Daly, P. W., Williams, D. J., Russell, C. T., and Keppler, E.: Particle signature of magnetic flux transfer events at the magnetopause, J. Geophys. Res., 86, 1628-1632, 1981.

Dungey, J. W.: Interplanetary magnetic field and the auroral zones, Phys. Rev. Lett., 6, 47-48, 1961.

Dunlop, M. W., Balogh, A., Cargill, P., Elphic, R. C., Fornacon, K.-H., Georgescu, E., Sedgemore-Schulthess, F., and the FGM team: Cluster observes the Earth's magnetopause: coordinated four-point magnetic field measurements, Ann. Geophys., 19, 1449-1460, 2001,

http://www.ann-geophys.net/19/1449/2001/.

Dunlop, M. W., Taylor, M. G. G. T., Davies, J. A., Owen, C. J., Pitout, F., Fazakerley, A. N., Pu, Z., Laakso, H., Bogdanova, Y.
V., Zong, Q.-G., Shen, C., Nykyri, K., Lavraud, B., Milan, S. E., Phan, T. D., Rème, H., Escoubet, C. P., Carr, C. M., Cargill, P., Lockwood, M., and Sonnerup, B.: Coordinated Cluster/Double Star observations of dayside reconnection signatures, Ann. Geophys., 23, 2867-2875, 2005,

http://www.ann-geophys.net/23/2867/2005/.

Elphic, R. C., Lockwood, M., Cowley, S. W. H., and Sandholt, P. E.: Flux transfer events at the magnetopause and in the ionosphere, Geophys. Res. Lett., 17, 2241-2244, 1990.

Escoubet, C. P., Fehringer, M., and Goldstein, M.: Introduction: the Cluster mission, Ann. Geophys., 19, 1197-1200, 2001,

http://www.ann-geophys.net/19/1197/2001/.

Fairfield, D. H.: Average and unusual locations of the Earth's magnetopause and bow shock, J. Geophys. Res., 76, 6700-6716, 1971.

Farrugia, C. J., Rijnbeek, R. P., Saunders, M. A., Southwood, D. J., Rodgers, D. J., Smith, M. F., Chaloner, C. P., Hall, D. S., Christiansen, P. J., and Woolliscroft, L. J. C.: A multi-instrument study of flux transfer event structure, J. Geophys. Res., 93, 14465$14477,1988$.

Fear, R. C., Fazakerley, A. N., Owen, C. J., Lahiff, A. D., Lucek, E. A., Balogh, A., Kistler, L. M., Mouikis, C., and Rème, H.: Cluster observations of bounday layer structure and a flux transfer event near the cusp, Ann. Geophys., 23, 2605-2620, 2005, http://www.ann-geophys.net/23/2605/2005/.

Greenwald, R. A., Baker, K. B., Dudeney, J. R., Pinnock, M., Jones, T. B., et al.: Darn/SuperDARN: A global view of the dynamics of high-latitude convection, Space Sci. Rev., 71, 761-796, 1995.

Haerendel, G., Paschmann, G., Sckopke, N., Rosenbauer, H., and Hedgecock, P. C.: The frontside boundary layer of the magnetopause and the problem of reconnection, J. Geophys. Res., 83, 3195-3216, 1978.

Harvey, C. C.: Spatial gradients and the volumetric tensor, in: Analysis Methods for Multi-Spacecraft Data, edited by: Paschmann, G. and Daly, P. W., pp. 307-348, ISSI, 1998.

Hasegawa, H., Sonnerup, B. U. Ö., Owen, C. J., Klecker, B., Paschmann, G., Balogh, A., and Rème, H.: The structure of flux transfer events recovered from Cluster data, Ann. Geophys., 24, 603-618, 2006,

http://www.ann-geophys.net/24/603/2006/.

Liou, K., Newell, P. T., and Meng, C.-I.: Characteristics of the solar wind controlled auroral emissions, J. Geophys. Res., 103, 17 543-17 557, 1998.

Lockwood, M., Fazakerley, A., Opgenoorth, H., Moen, J., van Eyken, A. P., Dunlop, M., Bosqued, J.-M., Lu, G., Cully, C., Eglitis, P., McCrea, I. W., Hapgood, M. A., Wild, M. N., Stamper, R.,W. Denig15, Taylor, M., Wild, J. A., Provan, G., Amm, O., Kauristie, K., Pulkkinen, T., Strømme, A., Prikryl, P., Pitout, F., Balogh, A., Rème, H., Behlke, R., Hansen, T., Greenwald, R., Frey, H., Morley, S. K., Alcayde, D., Blelly, P.-L., Donovan, E., Engebretson, M., Lester, M., Watermann, J., and Marcucci, M. F.: Coordinated Cluster and ground-based instrument observations of transient changes in the magnetopause boundary layer during an interval of predominantly northward IMF: relation to reconnection pulses and FTE signatures, Ann. Geophys., 19, 1613-1640, 2001, http://www.ann-geophys.net/19/1613/2001/.

Lockwood, M. and Smith, M. F.: The variation of reconnection rate at the dayside magnetopause and cusp ion precipitation, J. Geo- 
phys. Res., 97, 14 841-14 847, 1992.

Lockwood, M., Lanchester, B. S., Frey, H. U., Throp, K., Morley, S. K., Milan, S. E., and Lester, M.: IMF control of cusp proton emission intensity and dayside convection: implications for component and anti-parallel reconnection, Ann. Geophys., 21, 955-982, 2003,

http://www.ann-geophys.net/21/955/2003/.

Marchaudon, A., Cerisier, J., Bosqued, J., Dunlop, M., Wild, J., Décréau, P., Förster, M., Fontaine, D., and Laakso, H.: Transient plasma injections in the dayside magnetosphere: one-toone correlated observations by Cluster and SuperDARN, Ann. Geophys., 22, 141-158, 2004, http://www.ann-geophys.net/22/141/2004/

McWilliams, K. A., Yeoman, T. K., and Provan, G.: A statistical survey of dayside pulsed ionospheric flows as seen by the CUTLASS Finland HF radar, Ann. Geophys., 18, 445-453, 2000, http://www.ann-geophys.net/18/445/2000/.

Neudegg, D. A., Yeoman, T. K., Cowley, S. W. H., Provan, G., Haerendel, G., Baumjohann, W., Auster, U., Fornacon, K.-H., Georgescu, E., and Owen, C. J.: A flux transfer event observed at the magnetopause by the Equator-S spacecraft and in the ionosphere by the CUTLASS HF radar, Ann. Geophys., 17, 707-711, 1999 http://www.ann-geophys.net/17/707/1999/.

Neudegg, D. A., Cowley, S. W. H., McWilliams, K. A., Lester, M., Sigwarth, J., Haerendel, G., Baumjohann, W., Auster, U., Fornacon, K.-H., and Georgescu, E.: The UV aurora and ionospheric flows during flux transfer events, Ann. Geophys., 19, 179-188, 2001 , http://www.ann-geophys.net/19/179/2001/.

Owen, C. J. , Fazakerley, A. N., Carter, P. J., Coates, A. J., Krauklis, I. C., Szita, S., Taylor, M. G. G. T., Travnicek, P., Watson, G., Wilson, R. J., Balogh, A., and Dunlop M.W.: Cluster PEACE observations of electrons during magnetospheric flux transfer events, Ann. Geophys. 19, 1509-1522, 2001.

Paschmann, G., Haerendel, G., Papamastorakis, I., Sckopke, N., Bame, S. J., Gosling, J. T., and Russell, C. T.: Plasma and magnetic field characteristics of magnetic flux transfer events, J. Geophys. Res., 87, 2159-2168, 1982.

Pinnock, M., Rodger, A. S., Dudeney, J. R., Rich, F., and Baker, K. B.: High spatial and temporal resolution observations of the ionospheric cusp, Ann. Geophys., 13, 919-925, 1995, http://www.ann-geophys.net/13/919/1995/.

Provan, G., Yeoman, T. K., and Milan, S. E.: CUTLASS Finland radar observations of the ionospheric signatures of flux transfer events and the resulting plasma flows, Ann. Geophys., 16, 14111422,1998 http://www.ann-geophys.net/16/1411/1998/.

Ruohoniemi, J. M. and Baker, K. B.: Large-scale imaging of highlatitude convection with Super Dual Auroral Radar Network HF radar observations, J. Geophys. Res., 103, 20 797-20 811, 1998.
Ruohoniemi, J. M. and Greenwald, R. A.: Statistical patterns of high-latitude convection obtained from the Goose Bay HF radar observations, J. Geophys. Res., 101, 21 743-21 763. 1996.

Russell, C. T. and Elphic, R. C.: Initial ISEE magnetometer results: magnetopause observations, Space Sci. Rev., 22, 681-715, 1978.

Russell, C. T., Mellott, M. M., Smith, E. J., and King, J. H.: Multiple spacecraft observations of interplanetary shocks: Four spacecraft determination of shock normals, J. Geophys. Res., 88, 4739-4748, 1983.

Shi, Q. Q., Shen, C., Dunlop, M. W., Pu, Z. Y., Zong, Q.-G., Zhang, H., Xiao, C. J., Liu, Z. X., Lucek, E., and Balogh, A.: Motion of observed structures calculated from multi-point magnetic field measurements: Application to Cluster, Geophys. Res. Lett., 33 , L08109, doi:10.1029/2005GL025073, 2006.

Song, P., Le, G., and Russell, C. T.: Observational differences between flux transfer events and surface waves at the magnetopause, J. Geophys. Res., 99, 2309-2320, 1994.

Thomsen, M. F., Stansberry, J. A., Bame, S. J., Fuselier, S. A., and Gosling, J. T.: Ion and electron velocity distributions within flux transfer events, J. Geophys. Res., 92, 12 127-12 136, 1987.

Wild, J. A., Cowley, S. W. H., Davies, J. A., Khan, H., Lester, M., Milan, S. E., Provan, G., Yeoman, T. K., Balogh, A., Dunlop, M. W., Fornacon, K.-H., and Georgescu, E.: First simultaneous observations of flux transfer events at the high-latitude magnetopause by the Cluster spacecraft and pulsed radar signatures in the conjugate ionosphere by the CUTLASS and EISCAT radars, Ann. Geophys., 19, 1491-1508, 2001, http://www.ann-geophys.net/19/1491/2001/.

Wild, J. A., Milan, S. E., Cowley, S. W. H., Dunlop, M. W., Owen, C. J., Bosqued, J. M., Taylor, M. G. G. T., Davies, J. A., Lester, M., Sato, N., Yukimatu, A. S., Fazakerley, A. N., Balogh, A., and Rème, H.: Coordinated interhemispheric SuperDARN radar observations of the ionospheric response to flux transfer events observed by the Cluster spacecraft at the high-latitude magnetopause, Ann. Geophys., 21, 1807-1826, 2003, http://www.ann-geophys.net/21/1807/2003/.

Wild, J. A., Milan, S. E., Davies, J. A., Dunlop, M. W., Wright, D W., Carr, C. M., Balogh, A., Rème, H., Fazakerley, A. N., and Marchaudon: On the location of dayside magnetic reconnection during an interval of duskward oriented IMF, Ann. Geophys., 25, $1-20,2007$, http://www.ann-geophys.net/25/1/2007/.

Zheng, Y., Le, G., Slavin, J. A., Goldstein, M. L., Cattell, C., Balogh, A., Lucek, E. A., Reme, H., Eastwood, J. P., Wilber, M., Parks, G., Retino, A., and Fazakerley, A.: Cluster observation of continuous reconnection at daysidemagnetopause in the vicinity of cusp, Ann. Geophys., 23, 2199-2215, 2005, http://www.ann-geophys.net/23/2199/2005/. 